\title{
Not Known if ATRX Mutation Analysis Was Performed
}

National Cancer Institute

\section{Source}

National Cancer Institute. Not Known if ATRX Mutation Analysis Was Performed. NCI

Thesaurus. Code C160431.

An indication that it is not known whether AT RX mutation analysis was performed during the study. 